UNIVERSITY OF GOTHENBURG

SCHOOL OF BUSINESS, ECONOMICS AND LAW

WORKING PAPERS IN ECONOMICS

No 490

\title{
Bioeconomic model of spatial fishery management in developing countries
}

Wisdom Akpalu and Godwin K. Vondolia

February 2011

ISSN 1403-2473 (print)

ISSN 1403-2465 (online) 


\title{
Bioeconomic model of spatial fishery management in developing countries ${ }^{*}$
}

\author{
Wisdom Akpalu ${ }^{\dagger}$ \\ State University of New York at Farmingdale, US
}

Godwin K. Vondolia ${ }^{\ddagger}$

University of Gothenburg, Sweden

\begin{abstract}
Fishers in developing countries do not have the resources to acquire advanced technologies to exploit offshore fish stocks. As a result, the United Nations Convention on the Law of the Sea requires countries to sign partnership agreements with distant water fishing nations (DWFNs) to exploit offshore stocks. However, for migratory stocks, the offshore may serve as a natural marine reserve (i.e., a source) to the inshore (i.e., sink); hence these partnership agreements generate spatial externality. In this paper, we present a bioeconomic model in which a social planner uses a landing tax (ad valorem tax) to internalize this spatial externality. We found that the tax must reflect the biological connectivity between the two patches, intrinsic growth rate, the price of fish, cost per unit effort and social discount rate. The results are empirically illustrated using data on Ghana.
\end{abstract}

Keywords: Spatial fishery management, ad valorem tax, exclusive economic zone, developing countries

JEL Classification: N57, Q22, Q28, Q56, Q57

\footnotetext{
* Acknowledgement: The authors gratefully acknowledge financial support from the Swedish Agency for International Development Cooperation (Sida) to Environmental Economics Unit at the University of Gothenburg. We also acknowledge comments from Håkan Eggert, Jesper Stage and two anonymous reviewers. An earlier version was presented at the Fourth World Congress of Environmental and Resource Economists in Montreal, Canada and comments received from the audience are also appreciated.

${ }^{\dagger}$ Department of History, Economics and Politics, Farmingdale State College, State University of New York, 2350 Broadhollow RD, Farmingdale NY 11735, US; Tel.: + 1631794 6102; Email: akpaluw@farmingdale.edu.

${ }^{\ddagger}$ Department of Economics, University of Gothenburg, Box 640, 40530 Gothenburg, Sweden; Tel.: + 4631786 4170; Email: kofi.vondolia@economics.gu.se (Corresponding author).
} 


\section{INTRODUCTION}

Fisheries resources in many parts of the world are under threat of extinction due to high mortality rate and habitat destruction (FAO, 2004, 2009; Pauly et al., 1998). For example, a conservative estimation by Mullon et al. (2005) reveals that about 25\% of the 1519 FAO world fisheries have collapsed over the last 50 years. With the expected increase in global temperature and human population, the future of wild fisheries remains uncertain and bleak.

Patterns have emerged in natural resource management due to biological differences in habitats, deliberate regulatory measures instituted to control access to these resources in different habitats, different management regimes, differences in harvesting technologies, among other factors. The differences in the abundance of fish stocks in habitats are important requirement for ecosystem resilience since a biomass collapse in one habitat could be revived by the inflow of biomass from an adjacent habitat. According to Elmqvist et al. (2003), response diversity is a crucial requirement for ecosystem resilience ${ }^{1}$ and it is required to overcome the temporal and spatial variations in disturbances for continuous provision of ecosystem services and for reorganization. The management strategy that fails to recognize sub-stock diversity may as a consequence lead to overestimations of the stock levels, harvest potential, and subsequently to the collapse of fisheries resources (Sterner, 2007; Akpalu, 2009). Mills (1972) has also demonstrated that when spatial externalities are involved, resource allocation that does not consider the spatial externality will be inefficient.

\footnotetext{
${ }^{1}$ The response diversity refers to the differentials in responses to an environmental change among species that contribute to an ecosystem function.
} 
Despite seemingly adequate fisheries management policies in developed countries compared to developing countries, overfishing has been more pronounced in developed countries where improved technologies e.g. radar tracking device, bottom trawling, acoustic fish finders are employed in fisheries. As indicated by Pauly et al. (2002), technological progress tends to increase the catchability coefficient and renders ineffective any attempt that seeks to control fishing mortality by limiting only effort. Modernization of fishing gears and vessels, better knowledge on the spatial and temporal pattern of fish distribution have contributed to the depletion of fish stocks (Hilborn and Walters, 1992; Freon and Misund, 1999). Fisheries in developing countries are predominantly artisanal with simple technologies. The decline in global fish production from the introduction of new technologies enable many countries to view marine fisheries as a zero-sum game, a situation which paved way to intense competition among industrial countries for marine resources in developing countries (Iheduru, 1995).

The ratification of the United Nations Convention on the Law of the Sea in 1982 establishes rules governing the management of the oceans and marine resources. The convention also encourages partnership among countries for the management of marine resources. Typically, the convention stipulates that if a country cannot fully utilize the fisheries resources in its Exclusive Economic Zone (EEZ), the country must make this surplus available to fleet of other countries. Because of differences in fishing technologies, many developing countries have partnership agreements with developed countries to harvest the surplus marine fish stocks in the EEZ of the developing countries. However, access rights are restricted to areas (i.e., offshore) where artisanal fishers do not fish. Although the allocation of EEZ to coastal developing countries was 
potentially supposed to create significant wealth to improve the economies of such countries, paradoxically, the majority of such countries have drawn down their stocks and deepened poverty simultaneously (Hannesson, 2008; Atta-Mills et al., 2004; Adler and Sumaila, 2004). This could partly be due to the nature of appropriation agreement between the resource rich developing countries and the developed countries and inadequacy of policy instruments employed to regulate catch by the foreign fleets.

Different theoretical models have been developed to analyse the interactions between coastal developing countries and Distant Water Fishing Nations (DWFNs) in the management of fish stock in the former countries. For example, Clark and Munro (1987; 1991) and Munro (1994) provide a principal-agent analysis since coastal states do not exercise full control over the DWFNs. These studies focus on the terms and conditions of granting access but ignore the spatial interactions between offshore and inshore stocks. In addition, Bischi and Lamantia (2007) provide a discrete dynamic model to assess time evolution of fish stocks in an ecosystem (environment) that is divided into two adjacent zones with different fishing policies. The steady state stock levels and their stability properties are derived for the case where one of the patches is a protected area. Although these studies have addressed the strategic interactions involved in fisheries agreements between coastal states and DWFNs, they provide little policy measures that coastal states can use to better manage the marine resources and to regulate harvest in EEZs for optimum social welfare. Specifically, whereas the previous studies allude to the relevance of using the policy instruments such as tax to regulate offshore fishing in developing countries, the present study develops a spatial bio-economic model and derived an optimal landing tax for two policy objectives: to maintain the offshore stock at a reserve level or maximize the fishery 
manager's net benefit. The theoretical results have been empirically investigated using data on artisanal and semi-industrial fishing in Ghana. Our results indicate that to optimize economic rents, the social planner should impose a landing tax that should be increasing with intrinsic growth rate, the price of fish and the dispersion parameter but decreasing with the social discount rate and the cost per unit effort.

The remainder of the paper is organized as follows. Section 2 presents the theoretical model and derives some important results. The expression for the optimal tax is discussed in section 3. In section 4, we use data from Ghana to illustrate overfishing in both inshore and offshore fisheries and compute the value for the tax. The conclusion is presented in the last section, i.e., section 5 .

\section{THE MODEL}

In the fishery under consideration, artisanal fishers use rudimentary technologies to catch fish inshore. We begin by presenting a basic framework for which the offshore serves as a natural reserve (i.e., a source). After the basic framework, which provides a benchmark, we extend the model to a situation where the social planner grants access right to fleets from DWFNs. We extend the model to further derive an expression for an optimal landing fee (tax) that regulates harvest offshore. Finally, we characterize and provide empirical illustration of the optimal tax using data from artisanal and semi-industrial fishing in Ghana. 


\section{The Basic Framework}

Suppose that a given exclusive economic zone of a developing coastal country is subdivided into inshore and offshore. The domestic fishing fleets catch fishes from inshore whilst the offshore serves as a natural reserve. We assume that the social planner does not grant access rights to foreign fishing fleets and there are common species such as sardine, mackerel and tuna in both the inshore and offshore. Let $x_{i}$ denote the biomass density of fish in patch $i(i=1,2)$, where $x_{1}$ is the density inshore (patch 1 ) and $x_{2}$ is the density offshore (patch 2). ${ }^{2}$ For analytical tractability, we assume the biomass growth function is logistics. Thus

$$
f\left(x_{i}\right)=r_{i} x_{i}\left(1-x_{i}\right) ; i=1,2 \text {, }
$$

where $r_{i}$ is the intrinsic growth rate in patch $i$. Let the intrinsic growth rates in the two patched be equal, i.e., $r_{1}=r_{2}=r$. Furthermore, suppose the general cost function is

$$
c_{i}=c\left(x_{i}\right) h_{i} ; i=1,2
$$

where $h_{i}$ is harvest in patch $i$, and the following partial derivatives hold: $c_{x_{1}}=\frac{\partial c\left(x_{i}\right)}{\partial x_{i}}<0$, $c_{x_{1} x_{1}}=\frac{\partial^{2} c\left(x_{i}\right)}{\partial x_{i}^{2}}>0$ and $\frac{\partial c_{i}}{\partial h_{i}}=c\left(x_{i}\right)>0$. Let the specific cost per unit harvest be:

\footnotetext{
${ }^{2}$ The description of all notations used in the manuscript is presented in Table A1 of Appendix 1.
} 


$$
c_{i}\left(x_{i}\right)=\frac{\sigma_{i}}{x_{i}} ; i=1,2
$$

where $\sigma_{i}=\frac{c_{i}}{\alpha_{i}}, c_{i}$ is cost per unit effort, and $\alpha_{i}$ is catchability coefficient in patch $i$. Following Tuck and Possingham (1994) and Sanchirico and Wilen (1999) we assume a sinksource relationship between the two patches where the fish stock from deep oceans replenishes the inshore. Let the sink-source (inshore-offshore) relationship be

$$
\begin{aligned}
& \dot{x_{1}}=f\left(x_{1}\right)-h_{1}+d x_{2} \\
& \dot{x_{2}}=f\left(x_{2}\right)-h_{2}-d x_{2}
\end{aligned}
$$

where $\dot{x}_{1}$ represents the stock dynamics inshore, $\dot{x}_{2}$ is the stock dynamics offshore and $d x_{2}$ is the net migration of the stock from offshore to inshore ${ }^{3}$. The assumption of sink-source stems from environmental gradient in the ecosystems, which allows for specialization in the patches in terms of spawning and recruitment. Furthermore, the variability in environmental and biological factors, e.g. sea surface temperature (SST) in the Gulf of Guinea Large Marine Ecosystem that influence the abundance of planktons as well as stocks, generates this natural specialization (see e.g. Perry and Sumaila, 2007). Moreover, a coastward migratory pattern during the first half of the year is observed for round sardinella and other stocks (Brainerd, 1991). This evidence is supported by data on fishing in Ghana presented in section 4 of this paper.

\footnotetext{
${ }^{3}$ Some studies have assumed density-dependent dispersion between the offshore and inshore (see e.g. Bischi and Lamantia, 2007). However this has a serious weakness due to the implicit assumption that the stock distribution is uniform, and spawning takes place in each patch. Thus, since the environment or ecosystem is rarely uniform, the uniform distributions are rare in reality (King, 2007)
} 
In addition, if there is no human predation in patch 2 (i.e., $h_{2}=0$ ) the stock dynamics will be in steady state offshore (i.e., $\dot{x}_{2}=0$ ), so that equation (4) becomes

$$
f\left(x_{2}\right)=d x_{2}
$$

Using $f\left(x_{2}\right)=r x_{2}\left(1-x_{2}\right)$ we can re-write equation (5) as

$$
x_{2}=(r-d) r^{-1}
$$

and the inshore stock dynamic equation becomes

$$
\dot{x}_{1}=f\left(x_{1}\right)-h_{1}+\theta
$$

where $\theta=d(r-d) r^{-1}$. With harvest inshore, the social planner's instantaneous profit function is

$$
\pi\left(h_{1}, x_{1}\right)=p h_{1}-c\left(x_{1}\right) h_{1}
$$

where $p$ is the price per unit measure, say kilograms, of fish. The instantaneous profit is the difference between total revenue from harvest (i.e. $p h_{1}$ ) and the total cost of harvest(i.e. $\left.c\left(x_{1}\right) h_{1}\right)$. In a dynamic setting, the social planner will maximize the discounted profit function over the planning horizon subject to the resource dynamics. The social planner's optimization program is: 


$$
\max _{h_{1}} \int_{0}^{\infty}\left(p h_{1}-c\left(x_{1}\right) h_{1}\right) e^{-\delta t} d t
$$

subject to

$$
\begin{gathered}
\dot{x_{1}}=f\left(x_{1}\right)-h_{1}+\theta \\
0 \leq h_{1} \leq h_{1 \max }
\end{gathered}
$$

where $\delta>0$ is social discount rate. The corresponding current value Hamiltonian is:

$$
H=p h_{1}-c\left(x_{1}\right) h_{1}+\lambda\left(f\left(x_{1}\right)-h_{1}+\theta\right)
$$

where $\lambda=\lambda(t)$ is a costate variable. This formulation will produce three possible solutions including the bang-bang solution. The possible solutions are:

$$
h_{1}=\left\{\begin{array}{ccc}
0 & \text { if } & \lambda(t)>p-c\left(x_{1}\right) \\
h_{1}^{*} & \text { if } & \lambda(t)=p-c\left(x_{1}\right) \\
h_{1 \max } & \text { if } & \lambda(t)<p-c\left(x_{1}\right)
\end{array}\right.
$$

Assuming an interior solution exists (i.e., $h=h^{*}$ ), we have:

$$
\frac{\partial H}{\partial h_{1}}=p-c\left(x_{1}\right)-\lambda=0 \Rightarrow p-c\left(x_{1}\right)=\lambda
$$

Equation (14) implies that the net marginal benefit from harvest (i.e., $\left.p-c\left(x_{1}\right)\right)$ reflects the user cost of the stock ${ }^{4}$. The costate equation is:

\footnotetext{
${ }^{4}$ Henceforth, we suppress the time argument to minimize clutter.
} 


$$
\dot{\lambda}-\delta \lambda=c_{x_{1}} h_{1}-\lambda f_{x_{1}}
$$

where $f_{x_{1}}=\frac{\partial f\left(x_{1}\right)}{\partial x_{1}}$. From equation (15), in dynamic equilibrium, the sum of the capital gain (i.e., $\lambda$ ) and the stock effect (i.e., $-c_{x_{1}} h_{1}+\lambda f_{x_{1}}$ ) resulting from preserving a unit of the stock must equate the marginal benefit of harvesting the unit of the stock now and putting the proceed in a bank. Following Sydsaeter et al. (2005), the corresponding transversality condition is

$$
\lim _{t \rightarrow \infty} \lambda(t) e^{-\delta t}\left(x(t)-x^{*}(t)\right) \geq 0 \text { for all admissible } x(t)
$$

where $x^{*}(t)$ is the value of the stock of fish that maximizes the value function (i.e., equation 9). This condition must hold for $h^{*}$ and $x^{*}$ to maximize the value function. Moreover, it is assumed that the maximize Hamiltonian is concave in $x$ (i.e., the Arrow's weak sufficiency condition is satisfied). In the steady state $\dot{\lambda}=\dot{x}=0$ so that equation (15) becomes

$$
\lambda=\frac{-c_{x_{1}} h_{1}}{\left(\delta-f_{x_{1}}\right)}
$$

Using equation (17), we can rewrite equation (14) as

$$
p-c\left(x_{1}\right)=\frac{-c_{x_{1}} h_{1}}{\left(\delta-f_{x_{1}}\right)}
$$


where $f_{x_{1}}=r\left(1-2 x_{1}\right), \quad c_{x_{1}}=-\frac{\sigma_{1}}{x_{1}^{2}}$; and $h_{1}=f\left(x_{1}\right)+\theta$ in steady state. Substituting these into equation (18) gives

$$
p-\frac{\sigma_{1}}{x_{1}}=\frac{\sigma_{1}(f(.)+\theta)}{x_{1}^{2}\left(\delta-f_{x_{1}}\right)}
$$

With $\theta>0$, the current result (i.e., equation 18) provides a different trajectory for the fisheries resource management compared to the conventional result where $\theta=0$. Thus, if there is no natural reserve (or source), the trajectory that generates the optimal stock is:

$$
2 p r x_{1}^{2}+\left(\delta p-r p-r \sigma_{1}\right) x_{1}-\delta \sigma_{1}=0
$$

After substituting the specific functions, equation (18) can be restated as:

$$
2 r p x_{1}^{* 2}+\left(\delta p-r p-r \sigma_{1}\right) x_{1}^{*}-\delta \sigma_{1}-\frac{\sigma_{1} \theta}{x_{1}^{*}}=0
$$

From equations (20) and (21), the stock levels with and without reserve will be equal if $\theta=0$. But we know that $\theta=d\left(\frac{r-d}{r}\right)$ implying $r=d$ or $d=0$ implies $\theta=0$. Thus, the optimum stock levels with and without the natural reserve (source) are equal if $r=d$ or $d=0$. Furthermore, the stock level with the reserve is higher (less) than without the reserve if $r>d$ $(r<d)$. In addition, all else being equal, the optimum steady state stock in patch 1 is maximized at $d^{*}=\frac{1}{2} r$. This derives from equating a partial derivative of equation (20) with respect to the dispersion parameter to zero and solving for $d$ (i.e., $\frac{\partial x_{1}^{*}}{\partial d}=0$ ). The plot of the relationship between stock levels in patch $1\left(x_{1}\right)$ at various levels of dispersion parameter is presented in 
figure 1 . The parameter values conveniently chosen illustrate the relationship between the stock level and the dispersion parameter are $r=0.05, \delta=0.03, \sigma=0.8$ and $p=1$. The choice of the values are guided by the following assumptions: $r \geq \delta$, $d$ and $\sigma \leq p$.

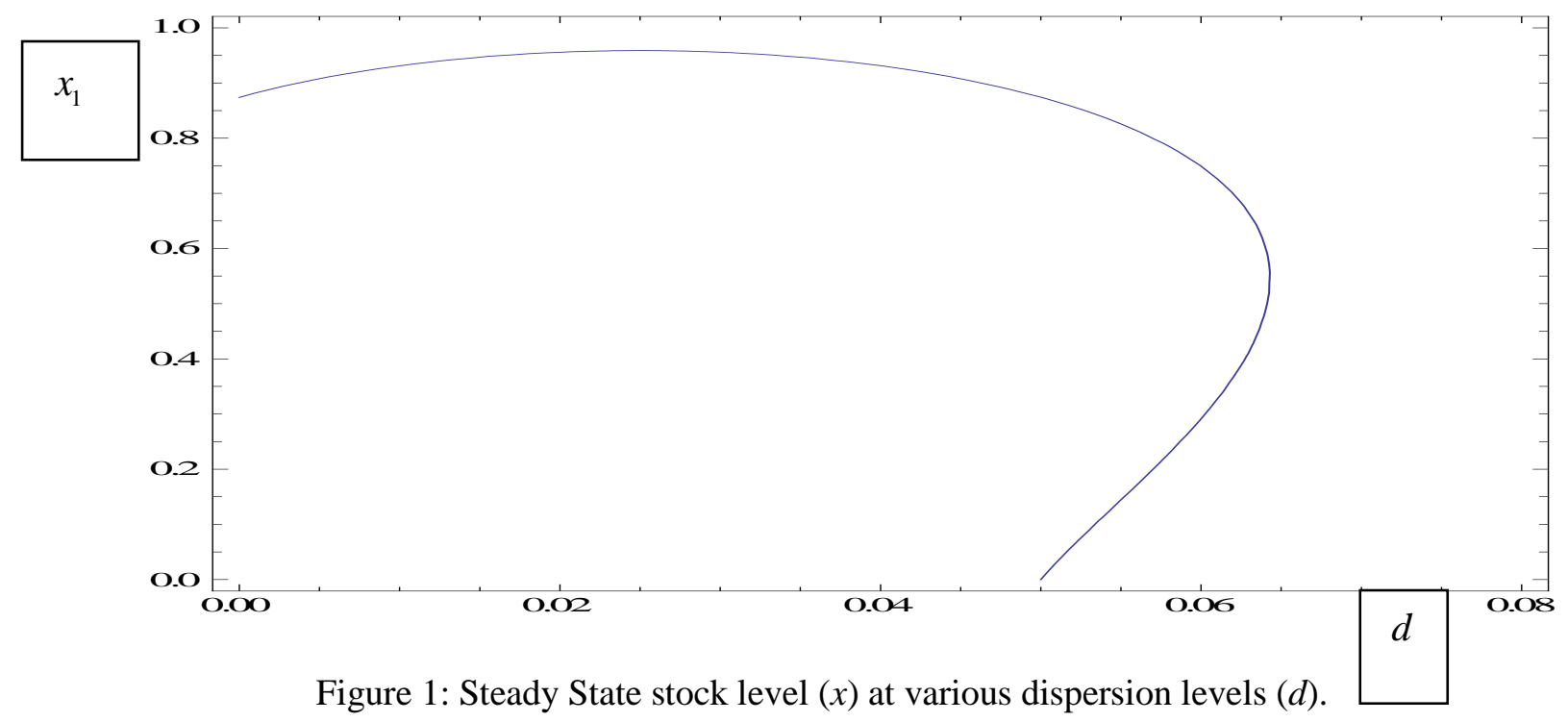

From Figure 1 above, it is clear the stock level in patch 1 increases, reaches a maximum, and decreases thereafter as the dispersion parameter increases. This underscores the fact that the stock level reaches a maximum at a certain level of dispersion. The maximum stock size is realized when $d=0.025$. Furthermore we investigate the impact on the equilibrium stock of changes in the parameter values chosen. The simulated results are presented in Table 1. 
Table 1: Comparison of conventional (i.e., $\theta=0$ ) and the new results(i.e., $\theta>0$ )

\begin{tabular}{|c|c|c|c|c|c|c|c|}
\hline$r$ & $\delta$ & $\sigma$ & $p$ & $d$ & $x_{\text {con }}$ & $x_{\text {new }}$ & $\frac{x_{\text {con }}}{x_{\text {new }}}$ \\
\hline 0.05 & 0.03 & 0.8 & 1 & 0.025 & 0.874456 & 0.878161 & 0.995781 \\
\hline 0.05 & 0.04 & 0.8 & 1 & 0.025 & 0.868466 & 0.873079 & 0.994716 \\
\hline 0.07 & 0.03 & 0.8 & 1 & 0.025 & 0.880425 & 0.884037 & 0.995914 \\
\hline 0.05 & 0.03 & 0.9 & 1 & 0.025 & 0.937883 & 0.941125 & 0.996555 \\
\hline 0.05 & 0.03 & 0.8 & 1.2 & 0.025 & 0.78735 & 0.791129 & 0.995223 \\
\hline 0.05 & 0.03 & 0.8 & 1 & 0.010 & 0.874456 & 0.876834 & 0.997288 \\
\hline 0.05 & 0.03 & 0.8 & 1 & 0.00 & 0.874456 & 0.874456 & 1.0000 \\
\hline
\end{tabular}

Results: All else being equal, the optimum steady state stock size in the sink (patch 1) is decreasing in social discount rate $(\delta)$, the price of fish ( $p)$, and catchability coefficient but increasing in cost per unit harvest $\left(c_{1}\right)$ and intrinsic growth rate.

The results obtained from the simulations have intuitive appeal. The positive relationship between discount rate and the stock level implies the more uncertain society is about the future, all other things being equal, the more likely it is to draw down the fish stock. Secondly, the higher the price the society receives by selling the fish caught, the lower the optimum stock in the management area. Thirdly, if the cost per unit effort increases or the catchability coefficient decreases, the optimum stock level in the management area will increase. Furthermore, a higher intrinsic growth rate will increase the stock within the management area. 
Extended Model: Human Predation inshore and offshore

\section{The Offshore Fisher's Problem}

In this section, we present the model for a representative offshore fleet. Suppose the government of the coastal developing country (i.e., social planner) licenses fleets to fish offshore at an advalorem royalty $\operatorname{tax}(\tau) .{ }^{5}$ Many studies have also demonstrated that landing fees are superior to e.g. quotas especially in the presence of uncertainties (Weitzman, 2002; Jensen and Vestergaard, 2003; Hannesson and Kennedy, 2005). In addition, an ad valorem royalty tax is flexible enough for cases where there are temporary hikes in the price of fish. With the tax, the instantaneous profit is the difference between total revenue (i.e., $(1-\tau) p h_{2}$ ) and total cost of harvest (i.e., $c\left(x_{2}\right) h_{2}$ ). The profit function will be maximized subject to the resource dynamics offshore. The optimization program is

$$
\max _{h_{2}} \int_{0}^{\infty}\left((1-\tau) p h_{2}-c\left(x_{2}\right) h_{2}\right) e^{-\delta t} d t
$$

subject to

$$
\dot{x_{2}}=g\left(x_{2}\right)-h_{2}-d x_{2}
$$

The current value Hamiltonian is given as

$$
H=(1-\tau) p h_{2}-c\left(x_{2}\right) h_{2}+\psi(t)\left(g\left(x_{2}\right)-h_{2}-d x_{2}\right)
$$

\footnotetext{
${ }^{5}$ An alternative is to use the quota to regulate the operations of the fleet from the DWFNs.
} 
The maximum principle (i.e., $\partial H / \partial h_{2}$ ) generates the following possible solutions

$$
h_{2}=\left\{\begin{array}{cl}
0 & \text { if } \psi(t)>(1-\tau) p-c\left(x_{2}\right) \\
h_{2}^{*} & \text { if } \psi(t)=(1-\tau) p-c\left(x_{2}\right) \\
h_{2 \max } & \text { if } \psi(t)<(1-\tau) p-c\left(x_{2}\right)
\end{array}\right.
$$

Assuming an interior solution exists, we have

$$
\begin{gathered}
\frac{\partial H}{\partial h_{2}}=(1-\tau) p-c\left(x_{2}\right)-\psi(t)=0 \\
(1-\tau) p-c\left(x_{2}\right)=\psi(t)
\end{gathered}
$$

The costate equation is

$$
\dot{\psi}(t)-\delta \psi(t)=c_{x_{2}}\left(x_{2}\right) h_{2}+\left(d-g_{x_{2}}\left(x_{2}\right)\right) \psi(t)
$$

In addition we assume the following transversality condition holds

$$
\lim _{t \rightarrow \infty} \psi(t) e^{-\delta t}\left(x(t)-x^{*}(t)\right) \geq 0
$$

Furthermore, in steady state we have $\dot{\psi}=0$ and equation (28) becomes

$$
\psi(t)=\frac{-c_{x_{2}}\left(x_{2}\right) h_{2}}{\delta+d-g_{x_{2}}\left(x_{2}\right)}
$$

Substituting equation (30) into equation (27) we have 


$$
(1-\tau) p-c\left(x_{2}\right)=\frac{-c_{x_{2}}\left(x_{2}\right) h_{2}}{\delta+d-g_{x_{2}}\left(x_{2}\right)}
$$

Using the specific functions, and $h_{2}=g\left(x_{2}\right)-d x_{2}$ in steady state, we have

$$
2 r p(1-\tau) x_{2}^{2}+\left(p(1-\tau)(\delta+d-r)-\sigma_{2} r\right) x_{2}-\sigma_{2} \delta=0 \Rightarrow x_{2}^{*}=x_{2}(\tau)
$$

Equation (32), is a quadratic function with two possible solutions but only one is admissible (i.e., $\left.x_{2}^{*}(\tau) \geq 0\right)$. The admissible solution is

$$
x_{2}^{*}(\tau)=\frac{r \sigma_{2}-p(d-r+\delta)(1-\tau)+\sqrt{\left(-r \sigma_{2}+p(d-r+\delta)(1-\tau)\right)^{2}+8 p r \delta \sigma_{2}(1-\tau)}}{4 p r(1-\tau)}
$$

The comparative static analysis indicates a positive relationship between the tax rate and the equilibrium stock size (i.e., $\frac{d x_{2}}{d \tau}>0$ ). The plot of the relationship between $x_{2}^{*}$ and $\tau$ is presented in Figure 2.

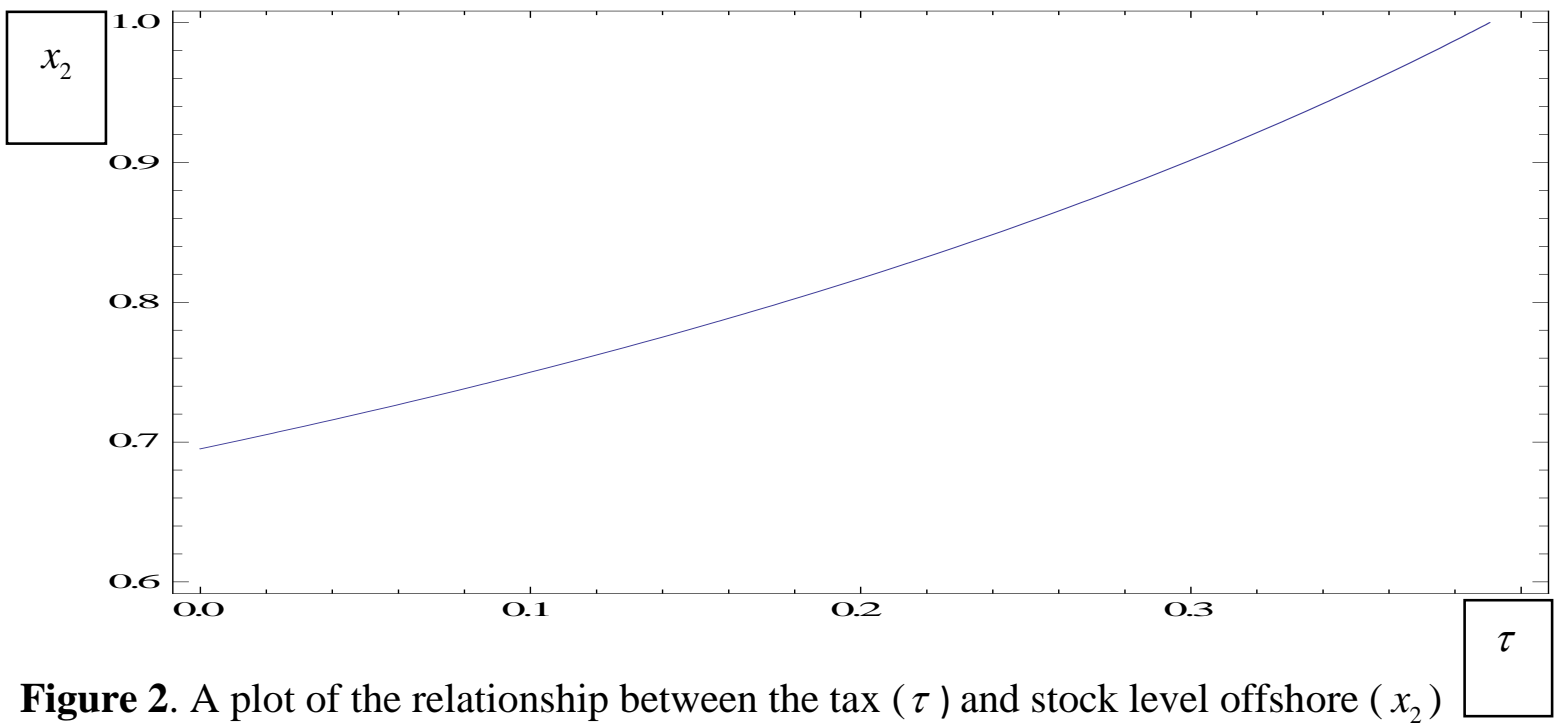


An intuitive explanation of the relationship between the stock offshore and the tax rate is quite obvious: the offshore stock corresponding to a higher tax rate will be lower than that of a lower tax rate.

The social planner's problem

To account for the preceding extension, the instantaneous profit function is modified so that the social planner's optimization program is:

$$
\max _{\tau, h_{1}} \int_{0}^{\infty}\left(p h_{1}-c\left(x_{1}\right) h_{1}+\tau p h_{2}\right) e^{-\delta t} d t
$$

subject to equation (4), i.e.,

$$
\begin{aligned}
& \dot{x_{1}}=f\left(x_{1}\right)-h_{1}+d x_{2} \\
& \dot{x_{2}}=f\left(x_{2}\right)-h_{2}-d x_{2}
\end{aligned}
$$

Since the foreign fleet must at least break even after paying the tax, we impose an additional constraint, i.e., the isoperimetric constraint. This constraint guarantees that the discounted net revenue from commercial fisheries is non-negative over the entire planning horizon. The examples of applications of the isoperimetric constraints can be found in e.g., Caputo (1998, 1999); Dogerty and Posey (1997); and Akpalu and Parks (2007). The constraint is specified as:

$$
\int_{0}^{\infty}\left[(1-\tau) p h_{2}-c\left(x_{2}\right) h_{2}\right] e^{-\delta t} d t \geq 0
$$


The current value Hamiltonian of the social planner's problem can be specified as:

$$
H=p h_{1}-c\left(x_{1}\right) h_{1}+\tau p h_{2}+\lambda\left(f(.)-h_{1}+d x_{2}\right)+\omega\left((1-\tau) p h_{2}-c\left(x_{2}\right) h_{2}\right)
$$

The first order condition with respect to harvest inshore (i.e., $\partial H / \partial h_{1}$ ) is:

$$
h_{1}=\left\{\begin{array}{ccc}
0 & \text { if } & \lambda>p-c\left(x_{1}\right) \\
h_{1}^{*} & \text { if } & \lambda=p-c\left(x_{1}\right) \\
h_{1 \max } & \text { if } & \lambda<p-c\left(x_{1}\right)
\end{array}\right.
$$

Also $\frac{\partial H}{\partial \tau}=0$, which gives

$$
p h_{2}(1-\omega)=0 \Rightarrow \omega=1
$$

Note that $\omega$ is not a user cost but a Lagrangian multiplier of the isoperimetric constraint. Since it takes a positive value, the isoperimetric constraint is binding. Assuming an interior solution exists for the harvest, the maximum principle can be restated as:

$$
p-c\left(x_{1}\right)=\lambda
$$

The costate equation is

$$
\dot{\lambda}-\delta \lambda=-\frac{\partial H}{\partial x_{1}}=c_{x_{1}}\left(x_{1}\right) h_{1}-\lambda f_{x_{1}}\left(x_{1}\right)
$$

In steady state $\dot{\lambda}=\dot{x}_{i}=0$ and equation (40) becomes 


$$
\lambda=\frac{-C_{x_{1}}\left(x_{1}\right) h_{1}}{\left(\delta-f_{x_{1}}\left(x_{1}\right)\right)}
$$

Substituting equation (41), $f_{x_{1}}\left(x_{1}\right)=r-2 r x_{1} ; c\left(x_{1}\right)=\frac{\sigma_{1}}{x_{1}}$ and $c_{x_{1}}\left(x_{1}\right)=-\frac{\sigma_{1}}{x_{1}^{2}}$ into equation (39), gives

$$
p x_{1}-\sigma_{1}=\frac{\sigma_{1} h_{1}}{x_{1}\left(\delta-r+2 r x_{1}\right)}
$$

Furthermore, substituting $h_{1}=f\left(x_{1}\right)+d x_{2}^{*}(\tau)$ into equation (42), gives

$$
2 p r x_{1}^{2}+\left(\delta p-r p-\sigma_{1} r\right) x_{1}-\delta \sigma_{1}-\sigma_{1} d x_{1}^{-1} x_{2}^{*}(\tau)=0 \Rightarrow x_{1}^{*}=x_{1}(\tau)
$$

However, due to the functional forms of some of the terms in the two equations, closed form solutions are difficult to obtain. Furthermore, from equation (33) we have shown the relationship between the stock in the sink and the tax rate is positive implying a relatively higher tax rate may results in a higher inshore optimum stock level, i.e.,

$$
\frac{d x_{1}^{*}}{d \tau}=\frac{\sigma_{1} d x_{1}^{-1}\left(\frac{\partial x_{2}^{*}(\tau)}{\partial \tau}\right)}{4 p r x_{1}+\left(\delta p-r p-\sigma_{1} r\right)+\sigma_{1} d x_{1}^{-2} x_{2}^{*}(\tau)}>0, \text { since }\left(\frac{\partial x_{2}^{*}(\tau)}{\partial \tau}\right)>0
$$

The relationship between inshore stock and the tax rate is plotted in Figure below: 


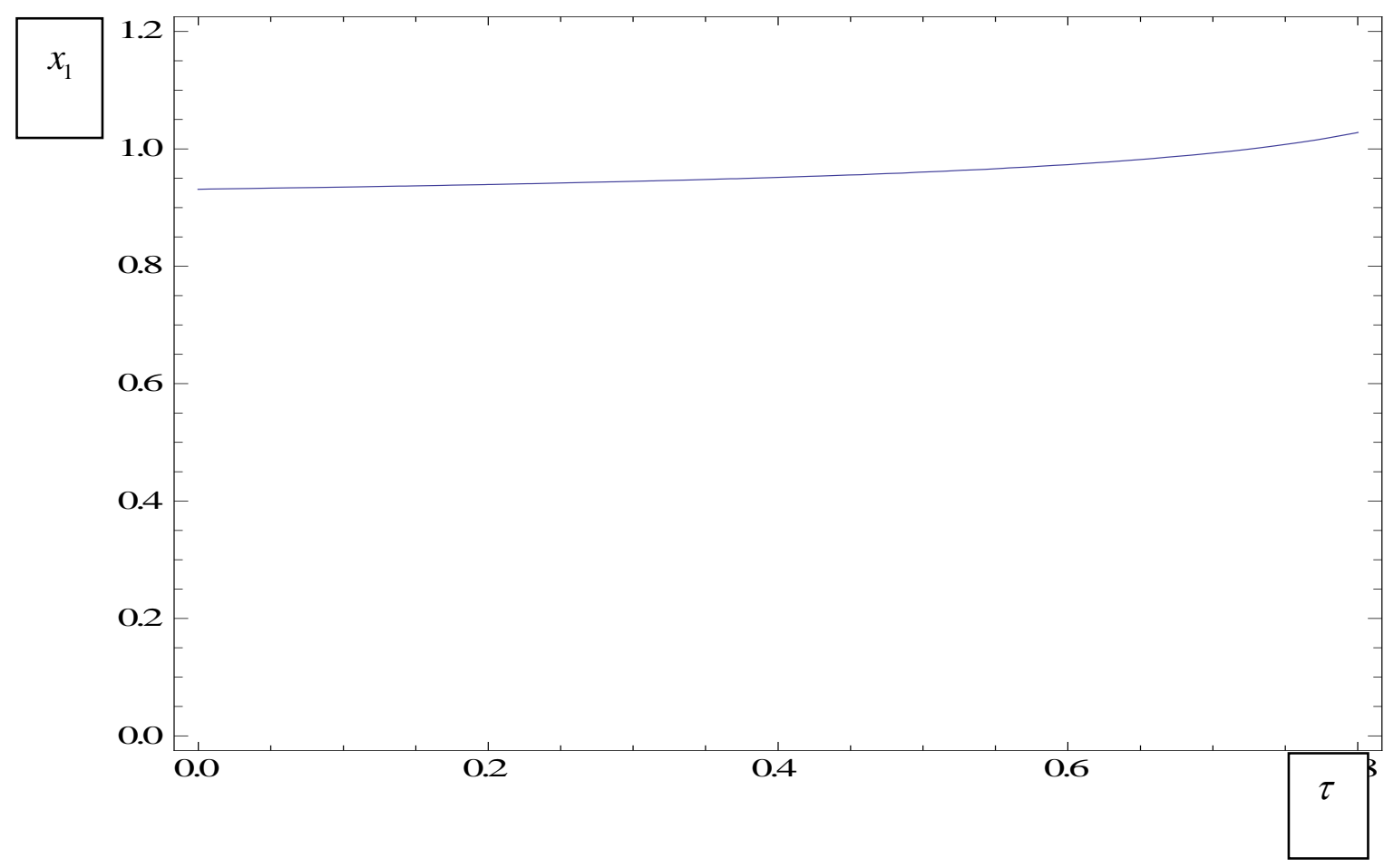

Figure 3. A plot of the relationship between the tax $(\tau)$ and stock level in inshore $\left(x_{1}\right)$

\section{Seeking an equilibrium royalty tax rate}

In this section, we present and characterize the expressions for equilibrium tax rate under two conditions: (1) if the social planner desires to keep the stock at the reserve level offshore, and (2) if the planner chooses the tax rate that maximizes net benefits.

\section{Policy Options to Guarantee Natural Marine Reserve Offshore}

The equilibrium tax that guarantees that the stock offshore is at its marine reserve level could be obtained by equating equation (6) to (33) and solving for $\tau$. Thus 


$$
\frac{r \sigma_{2}-p(d-r+\delta)(1-\tau)+\sqrt{\left(-r \sigma_{2}+p(d-r+\delta)(1-\tau)\right)^{2}+8 p r \delta \sigma_{2}(1-\tau)}}{4 \operatorname{pr}(1-\tau)}=\frac{(r-d)}{r}
$$

which gives

$$
\tau^{*}=1-\frac{\sigma_{2} r}{p(r-d)}
$$

Using the parameter values of $r=0.05, \delta=0.03, \sigma_{2}=0.8, d=0.001$ and $p=1$, the equilibrium tax is $\tau^{*}=0.184$. The following holds $\frac{\partial \tau^{*}}{\partial p}>0, \frac{\partial \tau^{*}}{\partial \sigma_{2}}<0, \frac{\partial \tau^{*}}{\partial d}<0$ and $\frac{\partial \tau^{*}}{\partial r}>0$. Intuitively, in order to keep the stock offshore at its marine reserve level, the tax rate must increase if the price of fish increases as this provides an incentive to the offshore fishers to catch more. Conversely, the tax must decrease if the cost of effort increases. Furthermore, if the dispersion of the stock from offshore to inshore increases, the tax rate should decrease in order to keep the stock at the reserve level. Finally, the tax rate must increase if the stock has a higher intrinsic growth rate implying that faster growing stocks must be taxed more.

\section{Policy options for maximizing net benefits}

To obtain the expression for the tax which maximizes total surplus of the fisheries manager, the two optimum stock expressions, i.e., $x_{2}^{*}(\tau)$ and $x_{1}^{*}(\tau)$ (i.e., equations 33 and 43 , respectively), 
are equated and $\tau$ is solved for. However the parametric expression for the tax rate is complex. As a result, the two functions are graphed to obtain a point of intersection. Using the parameter values chosen for illustrative purposes only (i.e., $r=0.05, \delta=0.03, d=0.001, \sigma=0.8$ and $p=1$ ), the estimated optimum tax rate of $\tau=0.028$. Clearly, this tax rate is lower than what is required to keep the stock offshore at the reserve level. However, the lower tax rate generates a larger net benefit to the social planner. The interpretations of these are straightforward. A lower tax value increase catch offshore and generates lower stock level offshore but brings in higher instantaneous profit margin to the social planner. Conversely, as expected, the higher tax rate although increases the stocks offshore and inshore, it lowers the profit of the social planner. Further sensitivity analysis presented in Table 2 reveals the tax is increasing in the price of fish and the dispersion parameter but decreasing in intrinsic growth of the stock, social discount rate and the cost of harvest.

Table 2: Sensitivity analysis of the tax

\begin{tabular}{|c|c|c|c|c|l|}
\hline$r$ & $\delta$ & $\sigma=\beta$ & $p$ & $d$ & $\tau$ \\
\hline 0.05 & 0.03 & 0.8 & 1 & 0.001 & 0.028 \\
\hline 0.06 & 0.03 & 0.8 & 1 & 0.001 & 0.025 \\
\hline 0.05 & 0.04 & 0.8 & 1 & 0.001 & 0.024 \\
\hline 0.05 & 0.03 & 0.9 & 1 & 0.001 & 0.026 \\
\hline 0.05 & 0.03 & 0.8 & 1.2 & 0.001 & 0.030 \\
\hline 0.05 & 0.03 & 0.8 & 1 & 0.002 & 0.054 \\
\hline
\end{tabular}




\section{Empirical Illustration of a sink-source dispersion: the case of offshore- inshore stocks in Ghana}

To provide an empirical illustration of the sink-source dispersion that drives our theoretical results and also calculate the optimal royalty tax, we investigate the offshore-inshore fishing in Ghana. The West African coastal countries, including Ghana, are facing declining catches of wild fish stocks due to over-capitalization and habitat degradation. In addition, numerous reports attribute the declining catches of inshore fishers to intensive catches by large and extensive European Union fleet who fish offshore (Atta-Mills et al., 2004). In Ghana, the EEZ is divided into Inshore Exclusive Zone (IEZ) and Offshore Exclusive Zone. According to Fisheries Act, 2002 Act 625, exclusively small semi-industrial vessel (SIV), canoes and recreational fishing vessels shall use the IEZ whilst large semi-industrial vessel, or industrial vessel and canoe support vessel could only strictly fish in the Offshore Exclusive Zone. This is not peculiar to Ghana as fisheries are often zoned such that each region adopts different sets of harvesting policies (Bischi and Lamantia, 2007). For numerical illustration, we use commercial species: mackerel and round and flat sardinella in the exclusive economic zone of Ghana.

Recent landing statistics for the artisanal fleet indicate that landings peaked in 1992, and then declined, due to overexploitation (Koranteng, 1998). In addition, the catch per unit effort of the semi-industrial fleet has generally declined throughout the period, a clear indication of overfishing. The descriptive statistics of the data is provided in Table A2 in the Appendix. From 
the descriptive statistics, the mean catch values for the three species are higher for artisanal fishers compared to the inshore fishers.

To investigate whether the stock of three major species (i.e., mackerel, round sardinella and flat sardinella) fished inshore and offshore are connected (i.e., the species are migratory), we perfomed a granger causality test on the harvest of each species. The results, which are reported in Table A3 in Appendix 2 indicates a unidirectional line of causality from offshore to inshore for the flat and round sardinela but bidirectional line of causality for mackerel in the two fisheries. This implies that the harvest of each of the species offshore could predict the harvest inshore. Invariably, these results confirm that the species are migratory and policies that address overfishing offshore could potentially affect the stock and harvest inshore.

\section{An estimate of equilibrium tax rate for Ghana}

To obtain an estimate for the royal tax rate that guarantees the stock offshore is at the reserve level, and the tax the maximizes net revenue within the management area in Ghana, we adapted figures from the literature. First, concerning the catch per unit effort and average revenue from catch, we used figures based on artisanal fishing in Ghana from Brinson et al. (2009). The median running cost and revenue per vessel (assuming that a vessel fishes 22 days in a month), which are used as proxies for CPUE and average revenue or price are \$95.88US and \$264.36US respectively. The intrinsic growth rate for sardines, which is one of the most commonly harvest stock in Ghana, adapted from $\mathrm{FAO}(2001)$ is 0.63 . Furthermore, we used a social discount rate of 3 percent. We could not obtain a specific value for the dispersion parameter for the sardines so we used $d=0.02$. The tax rate is calculated using these numbers and sentivity analysis is 
performed to illustrate how the tax rate could change in response to changes in some of the parameter values.

Based on these preceding values, the royalty tax that preserves the stock at the reserve level (i.e., combining equations 6 and 33 ) is $\tau=0.62$ and the corresponding figures that maxises net benefit of the social planner (combining equations 33 and 43) is $\tau=0.112$. From the two figures, the tax rate that maximizes net benefit is lower than the rate that mentains the stock offshore at the reserve level. Thus, if the objective of the social planner in Ghana is to maximise net benefit from harvest, the semi industrial fleets could be charged an approximate landing tax of $11.2 \%$ to internalize the spatial catch externality. The results from the sentivity analysis of our estimate are reported in Table 3.

Table 3. Ghana landing tax sensitivity

\begin{tabular}{|l|l|l|l|l|c|}
\hline \multicolumn{1}{|c|}{$r$} & \multicolumn{1}{|c|}{$\delta$} & \multicolumn{1}{c|}{$\sigma=\beta$} & \multicolumn{1}{c|}{$p$} & \multicolumn{1}{c|}{$d$} & $\tau$ \\
\hline 0.63 & 0.03 & 0.123682 & 0.341024 & 0.02 & 0.112 \\
\hline 0.70 & 0.03 & 0.123682 & 0.341024 & 0.02 & 0.102 \\
\hline 0.63 & 0.04 & 0.123682 & 0.341024 & 0.02 & 0.110 \\
\hline 0.63 & 0.03 & 0.123682 & 0.386479 & 0.02 & 0.121 \\
\hline 0.63 & 0.03 & 0.169136 & 0.341024 & 0.02 & 0.091 \\
\hline 0.63 & 0.03 & 0.123682 & 0.341024 & 0.03 & 0.158 \\
\hline
\end{tabular}

Note: Price and cost per unit harvest are in $\$ 10,000$ US. 
From Table 3, the optimal tax is increasing in the price of fish and dispersion parameter but decreasing in intrinsic growth rate, social discount rate, and the cost per unit harvest. The direction of relationships between the tax rate and the changes in the parameter values are consistent with what was obtained from the simulations that were based on the parameter values chosen conveniently.

In Ghana, foreign fleets are charged lincensing fees as well as fees to acquire fishing rights, which is a one time paymenmt for a period of time ${ }^{6}$. The licensing fees have been raised over time from 0.05 percent mean value of catch in 1995, to 0.6 percent in 1996 and to 1 percent in 1997. Beginning 2003, vessel licensing fees have been tied to size of the vessel and the types of species of fish landed. Thus, trawlers up to 300 Gross Registered Tonnage (GRT) pay US\$30 per GRT per annum, whilst, those in excess of 300 GRT pay US $\$ 55$ for every GRT in excess of the recommended 300 GRT (Hutchful, 2008). Compared to our estimate, the fee is very low and unlikely to generate the optimum rent from the fishery.

\section{CONCLUSIONS}

Many coastal developing countries lack the fishing technology to fully utilize the EEZ allocated under the United Nations Convention on the Law of the Sea. As a result, these countries enter into agreements with Distant Water Fishing Nations (DWFNs) to maximize rents from wild fish catches. Although short term rents from taxes on offshore catches are crucial for such poor countries, long-term stream of overall economic rents could easily be jeopardized since most

\footnotetext{
${ }^{6}$ As at 2003, a company is supposed to pay an application and processing fees of US\$500 and US\$010 000, respectively.
} 
stocks are generally migratory and given that the offshore serves as a natural reserve (evidence from the fishery in Ghana has been provided in support of this). In addition, the natural reserve offshore improves the resilience of the exclusive economic zone. In this paper, we have provided a theoretical model to shed light on the problem and developed optimum policy instruments that these countries could employ to maximize overall rents for catches in the EEZ.

We found that coastal developing countries could use ad valorem royalty tax to regulate catch offshore and maximize overall economic benefit. The royalties should reflect the ecology of the marine ecosystem as well as relevant socio-economic characteristics. Thus, the royalty should reflect the stock externality of harvesting offshore, dispersion or connectivity between the two subdivisions, the intrinsic growth of the fisheries, catchability coefficient of species, the discount rate of the society and the price of the fishes. In effect, these countries should balance the opportunity costs of the access rights against the benefits from granting access rights. 


\section{References}

Akpalu, W., 2009. Economics of biodiversity and sustainable fisheries management, Ecological Economics 68(2009): 2729 - 2733.

Akpalu, W. and P. Parks, 2007. Natural resource use conflict: gold mining in tropical rainforest in Ghana, Environment and Development Economics 12: 55 - 72.

Alder, J. and U. R. Sumaila, 2004. Western Africa: A Fish Basket of Europe Past and Present, Journal of Environment and Development 13 (2): 156 - 178.

Atta-Mills, J., J. Alder and U. R. Sumaila, 2004. The decline of a regional fishing nation: the case of Ghana and West Africa, Natural Resources Forum 28: 13-21.

Bischi, G. I. and F. Lamantia, 2007. Harvesting dynamics in protected and unprotected areas, Journal of Economic Behavior and Organization 62: 348 - 370.

Brainerd, T. R., 1991. The Sardinella Fishery off the Coast of West Africa: The Case of a Common Property Resource, Paper presented at the $2^{\text {nd }}$ Annual Conference of the International Association for the Study of Common Property, September 26 - 29, 1991, University of Manitoba, Winnipeg, Canada.

Brinson, A. A., D. J. Die, P. O. Bannerman and Y. Diatta, 2009. Socioeconomic performance of West African Fleets that target Atlantic billfish, Fisheries Research 99 (2009): 55-62.

Caputo, R. M., 1999. Economic characterization of reciprocal isoperimetric control problems revisited, Journal of Optimization Theory and Applications 101: 723-730.

Caputo, R. M., 1998. Economic characterization of reciprocal isoperimetric control problems, Journal of Optimization Theory and Applications 98: 325-350.

Clark, F. H. and Munro, G. R., 1987, Coastal States, Distant Water Fishing Nations and Extended Jurisdiction: A Principal - Agent Analysis, Natural Resource Modeling 2: 19 $-26$.

Doherty, N. and L. Posey, 1997. Availability crises in insurance markets: optimal contracts with asymmetric information and capacity constraints, Journal of Risk and Uncertainty 15: 55-80. 
Elmqvist, T., C. Folke, M. Nyström, G. Peterson, J. Bengtsson, B. Walker and J. Norberg, 2003. Response diversity, ecosystem change and resilience, Frontiers in Ecology and the Environment 1(9): 488-494.

FAO Fisheries Department, 2009. The State of World Fisheries and Aquaculture 2008 United Nations Food and Agriculture Organisation, Rome.

FAO Fisheries Department, 2004. State of the World Fisheries and Aquaculture 2004. United Nations Food and Agriculture Organization, Rome.

FAO Fisheries and Aquaculture Department, 2001. Report of the FAO Working Group on the Assessment of Small Pelagic Fish off Northwest Africa, Nouadhibou, Mauritania 24-31 March, 2001, United Nations Food and Agriculture Organization, Rome.

Freon, P. and O. A. Misund, 1999. Dynamics of Pelagic Fishing Distribution and Behaviour:

Effects on Fisheries and Stock Assessment, Fishing News Books, Oxford.

Hannesson, R., 2008. The exclusive economic zones and economic development in Pacific island countries, Marine policy 32 (6): 886 - 897.

Hannesson, R. and J. Kennedy, 2005. Landing Fees and Fish Quotas, Land Economics 81 (4): 518-529.

Hannesson, R., 2002. The Economics of Marine Reserves, Natural Resource Modeling 15 (3): 273-290.

Hilborn, R. and C. J. Walters, 1992. Quantitative Fisheries Stock Assessment: Choice, Dynamics and Uncertainty. Chapman and Hall, New York.

Hutchful, G., 2008. Financing fisheries management: the Ghanaian situation. In R. Metzner (comp.). Report of the Expert Consultation on Low-cost Fisheries Management Strategies and Cost Recovery, Georgetown, Guyana, 4-7 September 2007. FAO Fisheries and Aquaculture Report. No. 853. Rome, FAO. pp. 207-235.

Iheduru, O. C., 1995. The Political Economy of Euro-African Fishing Agreements, Journal of Developing Areas 30(1): 63 - 90.

Jensen, F. and N. Vestergaard, 2003. Prices versus Quantities in Fisheries Models, Land Economics 79: 415-425.

King, M., 2007. Fisheries Biology, Assessment and Management, Blackwell Publishing, Oxford.

Koranteg, K. A., 1998. The Impacts of Environmental Forcing on the Dynamics of Demersal Fishery Resources of Ghana, PhD Dissertation, University of Warwick Coventry. 
Mills, E. S., 1972. Markets and Efficient Resource Allocation in Urban Areas, Swedish Journal of Economics 74: 100-113.

Mullon, C., P. Fréon and P. Curry, 2005. The dynamics of collapse in world fisheries, Fish and Fisheries 6 (2): 111-120.

Munro, G. R., 1994. Coastal States and Distant Water Fleets under Extended Jurisdiction: The Search for Optimal Incentive Schemes in Basar, T. and A. Haurie, (eds.), Advances in Dynamic Games and Applications, Annals of the International Society of Dynamic Games, Birkhäuser, Boston.

Pauly, D., V. Christensen, S. Guenette, T. J. Pitcher, U. R. Sumaila, C. J. Walters, R. Watson and D. Zeller, 2002. Towards sustainability of world fisheries, Nature 418: 689 - 695.

Pauly, D., V. Christensen, J. Dalsgaard, R. Froese and E. C. Torres Jr., 1998. Fishing down marine food webs, Science 279: 860-863.

Perry, R. I. and U. R. Sumaila, 2007. Marine ecosystem variability and human community responses: The case of Ghana, West Africa, Marine Policy 31: 125 - 134.

Sanchirico, J. N. and J. E. Wilen, 1999. Bioeconomics of Spatial Exploitation in a Patchy Environment, Journal of Environmental Economics and Management 37: 129-150.

Sterner, T., 2007. Unobserved diversity, depletion and irreversibility - The importance of subpopulations for management of cod stocks, Ecological Economics 61: 566-574.

Sydsaeter, K., A. Strøm and P. Berck, 2005. Economists’ Mathematical Manual, SpringerVerlag, Berlin.

Tuck, G. N. and H. P. Possingham, 1994. Optimal harvesting strategies for metapopulation, Bulletin of Mathematical Biology 56 (1): 107-127.

Weitzman, M. L., 2002. Landing fees vs Harvest Quotas with Uncertain Fish Stock, Journal of Environmental Economics and Management 43 (2): 325-338. 


\section{APPENDIX 1: TABLES}

Table A1: Description of Variables and Parameters

\begin{tabular}{|l|l|}
\hline Variables & Description \\
\hline$x_{1}$ & Biomass in patch 1 (i.e. for artisanal fisheries zone) \\
\hline$x_{2}$ & Cost per unit effort in patch 1 \\
\hline$c_{1}$ & Cost per unit effort in patch 2 \\
\hline$c_{2}$ & Catchability coefficient in patch 1 or in artisanal fisheries \\
\hline$\alpha_{1}$ & Catchability coefficient in patch 2 or in commercial fisheries \\
\hline$\alpha_{2}$ & Generic discount rate or social planner's discount rate \\
\hline$\delta$ & Normalized cost per unit effort by catchability coefficient \\
\hline$\sigma_{1}, \sigma_{2}$ & \\
\hline
\end{tabular}

Table A2: Descriptive statistics of Canoe and Semi-industrial Catch in Ghana (1971 - 2007)

\begin{tabular}{clccc}
\hline \multicolumn{1}{c}{ Species } & Type of Vessel & Observations & Mean Catch (tons) & Standard Deviation \\
\hline \multirow{2}{*}{ Round Sardinella } & Canoe & 37 & 48909.14 & 30522.04 \\
& Semi-industrial & 37 & 3360.765 & 2119.29 \\
\cline { 2 - 4 } Flat Sardinella & Canoe & 36 & 13924.23 & 4939.27 \\
& Semi-industrial & 36 & 702.4642 & 665.2124 \\
\cline { 2 - 3 } Chub Mackerel & Canoe & 37 & 4454.018 & 5153.297 \\
& Semi-industrial & 36 & 931.6838 & 894.7166 \\
\hline
\end{tabular}


Table A3: Granger causality between canoe and semi-industrial catch of three species

\begin{tabular}{|c|c|c|c|c|}
\hline Fisheries & Equation & Fisheries & Excluded & Chi Square \\
\hline \multirow[t]{2}{*}{ Canoe } & Round sardinella & \multirow[t]{2}{*}{ Semi-industrial } & Round sardinella & $14.319 * *$ \\
\hline & Round sardinella & & ALL & $14.319 * *$ \\
\hline \multirow[t]{2}{*}{ Semi-industrial } & Round sardinella & \multirow[t]{2}{*}{ Canoe } & Round sardinella & 3.6743 \\
\hline & Round sardinella & & ALL & 3.6743 \\
\hline \multirow[t]{2}{*}{ Canoe } & Flat sardinella & \multirow[t]{2}{*}{ Semi-industrial } & Flat sardinella & $34.669 * * *$ \\
\hline & Flat sardinella & & ALL & $34.669 * * *$ \\
\hline \multirow[t]{2}{*}{ Semi-industrial } & Flat sardinella & \multirow[t]{2}{*}{ Canoe } & Flat sardinella & 0.36298 \\
\hline & Flat sardinella & & ALL & 0.36298 \\
\hline \multirow[t]{2}{*}{ Canoe } & Chub mackerel & \multirow[t]{2}{*}{ Semi-industrial } & Chub mackerel & $22.682 * * *$ \\
\hline & Chub mackerel & & ALL & $22.682 * * *$ \\
\hline \multirow[t]{2}{*}{ Semi-industrial } & Chub mackerel & \multirow[t]{2}{*}{ Canoe } & Chub mackerel & $26.495 * * *$ \\
\hline & Chub mackerel & & ALL & $26.495 * * * *$ \\
\hline
\end{tabular}

* Significant at 10\%, ** Significant at 5\% and *** Significant at 1\%. 